\title{
The relationships and directions between electricity consumption and economic growth for four regions in China
}

\author{
XIAOQING MA ${ }^{1}$, RONG LI $^{2}, \mathrm{KL} \mathrm{LO}^{2}$ \\ ${ }^{1}$ School of Economics and Management, Shanghai University of Electric Power, No.2103, \\ Ping Liang Road, Shanghai, China \\ ${ }^{2}$ Department of Electronic and Electrical Engineering, University of Strathclyde, 204 \\ George Street, Glasgow, G1 1XW, UK
}

\begin{abstract}
We investigate the relationship between electricity consumption and economic growth for four regions in China. The empirical results show that there are cointegration relationships and short-run bidirectional causality for the four regions. Over the long-run, there is bidirectional in the west, there is unidirectional causality running from economic growth to electricity consumption for the coastal region, whilst there is unidirectional causality running from electricity consumption to economic growth for the northeast and central area. The panel FMOLS estimates also support these results. This can provide a policy-making of demand forecasts and investment orientation in the short and long term.
\end{abstract}

Keywords: electricity consumption, economic growth, relationship and directions.

\section{Introduction}

\subsection{Background}

In the past two decades, China has achieved rapid economic growth in the world. The installed generation capacity in China amounted to more than $870 \mathrm{GW}$ and electricity consumption is more than 3600TWH. The coordination of electrici- ty consumption and economy is crucial to sustain economic growth. Because of the differences of economic growth and industrial developments in different areas of China, this paper is attempted to investigate the relationship and causality between electricity consumption and economic growth in China by panel-based methods.

\subsection{Literature review}

Yang (2000), Narayan and Smyth (2005), $\mathrm{Ho}$ and Siu (2007), $\mathrm{Hu}$ and Lin (2008) Odhiambo (2009) and Akinlo (2009)used standard Granger causality test to support that there was bidirectional causality between electricity consumption and growth in different countries.Narayan and Smyth (2009) employed panel methods on 6 Middle Eastern countries and they found bidirectional causality existed between electricity consumption and growth.

Shiu and Lam (2004), Yuan et al. (2008) asserted that there was a unidirectional causality running from electricity consumption to economic growth in China. Zhang and Cheng (2009) did not support the above opinion. Li et al. (2010) classified 30 China provinces into two parts, Wu et al. (2008) divided China into three parts (east, central and west parts) to investigate the relationship between energy consumption and economic growth. 


\subsection{Methodology}

Firstly, in order to avoid spurious correction between LnEC and LnGDP, the paper uses panel unit root test to identify the order of each panel. Secondly, the paper tests the cointegration between these two variables in each panel by employing the heterogeneous panel cointegration test developed by Pedroni (1999). Then, the paper applies the panel vector error correction model to investigate the direction of the causal relation between the variables after establishing the cointegration relationship. Finally, to estimate panel long-run elasticity, the paper applies the fully modified and dynamic OLS techniques.

\section{Definition of variable and classifi- cation of data}

\subsection{Definition of variable}

This paper uses logarithmic electricity consumption ( $\ln E C_{i t}$ ) and logarithmic real GDP ( $\ln G D P_{i t}$, based on 1978's price) to stand for electricity consumption and economic growth of each province respectively for the $1985-2009$ period (28 provinces excluding CHONGQIN, HAINAN and TIBET). The real GDP are converted by the nominal GDP. The nominal GDP data and GDP deflators are all from China Statistical Yearbooks (2010).

\section{2classification of data}

In order to reflect the difference in economic growth and electricity industry development in each province, 28 provinces are classified as four panels, which include 3 North-eastern provinces (Liaoning, Jilin and Heilongjiang), 7 betterdeveloped provinces (Shanghai, Beijing, Tianjin, Zhejiang, Jiangsu, Guangdong and Shandong), 9 less-developed provinces (Fujian, Hebei, Hubei, Shaanxi,
Shanxi, Sichuan, Henan, Hunan and Jiangxi) and 9 under-developed provinces (Neimenggu, Xinjiang, Qinghai, Ningxia, Anhui, Guangxi, Yunnan, Gansu and Guizhou). The classification of 28 provinces is based on GDP per head, industry production per head and industrial structure.

\section{Empirical results and analysis}

\section{1. Panel unit root test results}

The results of panel unit root tests with and without time trend term for LnGDP and LnEC for four areas of China respectively. It can be inferred that the unit root hypothesis cannot be rejected when the variables are taken in levels. However, when first differences are used, the hypothesis of unit-root non-stationary is rejected at the $1 \%, 5 \%$ or $10 \%$ level of significance. Therefore, obviously, LnGDP and LnEC are I(1) process in each panel.

\subsection{Panel cointegration test results}

Table1. Panel cointegration test results

\begin{tabular}{lllll}
\hline Within demension & Northeast & Coastal & Central & West \\
\hline Panel v-Statistic & 0.813 & 0.648 & $2.201^{* *}$ & $1.798^{* *}$ \\
Panel rho-Statistic & -1.134 & 0.038 & -1.438 & $-1.364^{*}$ \\
Panel PP-Statistic & $-1.896^{* *}$ & -0.059 & $-1.678^{* *}$ & $-1.799^{* *}$ \\
Panel ADF Statistic & $-1.849^{* *}$ & -1.269 & $-3.075^{* * *}$ & $-2.451^{* * *}$ \\
\hline Between dimension & & & & \\
Group PP-Statistic & -0.208 & 0.293 & 0.044 & -0.129 \\
Group rho-Statistic & $-1.492^{*}$ & -0.175 & -0.841 & -0.948 \\
Group ADF-Statistic & $-1.478^{*}$ & $-2.085^{* *}$ & $-3.536^{* * *}$ & -2.453 \\
\hline
\end{tabular}

Note: $* * *, * *$ and $*$ indicates statistical significance at the $1 \%, 5 \%$ and $10 \%$ level, respectively.

\subsection{Panel FMOLS results}

For the different regions, a $1 \%$ increase in $\log$ electricity consumption leads to $1.83 \%, 1.22 \%, 1.26 \%$ and $0.97 \%$ increase in log GDP in the northeast, coastal, central and west regions, respectively. The significant high FMOLS values of northeast provinces indicate the need for separating this region. 
Table2. FMOLS results( West)

\begin{tabular}{lll}
\hline & FMOLS & t-stat \\
Neimenggu & $0.92 * * *$ & $27.51 * * *$ \\
Xinjiang & $0.88 * * *$ & $56.12 * * *$ \\
Qinghai & $0.76 * * *$ & $14.82 * * *$ \\
Ningxia & $0.78 * * *$ & $26.46 * * *$ \\
Anhui & $1.25 * * *$ & $15.64 * * *$ \\
Guangxi & $1.08 * * *$ & $78.56 * * *$ \\
Yuanan & $0.92 * * *$ & $29.59 * * *$ \\
Gansu & $1.30 * * *$ & $24.51 * * *$ \\
Guizhou & $0.85 * * *$ & $32.43 * * *$ \\
Group-mean & $0.97 * * *$ & $101.88 * * *$ \\
\hline
\end{tabular}

Table3. FMOLS results(Coastal)

\begin{tabular}{lll}
\hline & FMOLS & t-stat \\
shanghai & $1.38 * * *$ & $58.40 * * *$ \\
beijing & $1.35 * * *$ & $59.42 * * *$ \\
tianjin & $1.47 * * *$ & $37.47 * * *$ \\
zhejiang & $0.99 * * *$ & $24.63 * * *$ \\
jiangsu & $1.15 * * *$ & $17.08 * * *$ \\
Guangdong & $1.00 * * *$ & $47.95 * * *$ \\
Shandong & $1.23 * * *$ & $20.89 * * *$ \\
Group-mean & $1.22 * * *$ & $100.47 * * *$ \\
\hline
\end{tabular}

Table4. FMOLS results(Northeast)

\begin{tabular}{lll}
\hline & FMOLS & t-stat \\
Liaoning & $1.61 * * *$ & $28.54 * * *$ \\
Jilin & $1.98 * * *$ & $21.44 * * *$ \\
Heilongjiang & $1.88 * * *$ & $14.50 * * *$ \\
Group-mean & $1.83 * * *$ & $37.23 * * *$ \\
\hline
\end{tabular}

Table5. FMOLS results(Central)

\begin{tabular}{lll}
\hline & FMOLS & t-stat \\
fujian & $1.09 * * *$ & $31.13 * * *$ \\
hebei & $1.20 * * *$ & $21.14 * * *$ \\
hubei & $1.43 * * *$ & $24.46 * * *$ \\
shanxi2 & $1.32 * * *$ & $34.25 * * *$ \\
shanxi & $1.10 * * *$ & $32.74 * * *$ \\
Sichuan & $1.50 * * *$ & $12.47 * * *$ \\
Henan & $1.16 * * *$ & $30.48 * * *$ \\
Hunan & $1.26 * * *$ & $24.47 * * *$ \\
Jiangxi & $1.27 * * *$ & $15.73 * * *$ \\
Group-mean & $1.26 * * *$ & $75.62 * * *$ \\
\hline
\end{tabular}

Note: $* * *$ indicates statistical significance at the $1 \%$ level.

\section{Conclusion and policy implications}

\subsection{Conclusion}

We applies the panel data for log electricity consumption and log GDP for 28 provinces from 1985 to 2009 . The results show that there are bidirectional causalities between electricity consumption and growth for each panel in the short-run. Over the long term, there are bidirectional causality for the west. For coastal provinces, the direction is running from economic growth to electricity consumption, while in the northeast and central provinces the opposite is true. Northeast and central provinces have higher long-run elasticity of electricity consumption to GDP than other provinces, and it also means their electricity efficiency is higher than other provinces.

\subsection{Policy suggestions}

Firstly, the electricity investment strategy-making should take account of the electricity elasticity and causality direction of different regions. In Northeast the government needs to encourage investment in power industry as a priority. The coastal region need to development irregular power generation. Central and west regions have bidirectional causality between electricity consumption and economic growth. Hence the government ought to promote the coordinated development of economy and electrical industry while they step up investment on power industry.

Secondly, consideration of the bottleneck of power supply, the industry option of these provinces should more incline to some low electricity and energy cost industries. The coastal region should quicken industrial structure update and adjustment, focus on the development of the third industry, the high electricity and energy consumption industries could be transferred to the central and west regions. 
Thirdly, ultra-high-voltage (UHV) electric transmission can be treated as a feasible scheme to remit electricity surplus or deficit problem in different regions. With regard to these relatively developed provinces, the problem of lack of electricity always exists. Therefore, through constructing cross-regional ultrahigh-voltage electric transmission network to remit electricity supply and demand imbalance among different regions is worth consideration.

\section{Acknowledgements}

This research work is supported by Foundation of Shanghai Board of Education Project 2011 (No. 12ZS162). The authors gratefully acknowledge their support.

\section{Corresponding author:}

\section{XIAOQING MA}

Telephone: 15921299348

Mail:maxqing95@hotmail.com

\section{References}

[1] Akinlo, A.E., 2009. Electricity consumption and economic growth in Nigeria: evidence from cointegration and co-feature analysis. Journal of Policy Modeling.

[2] Database, C.S.Y., 2011. http://data.cnki.net/navi/NaviDefault. aspx. CNKI Knowledge Network Service Platform.

[3] Ho, C.-Y., Siu, K.W., 2007. A dynamic equilibrium of electricity consumption and GDP in Hong Kong: an empirical investigation. Energy Policy 35(4), 2507-2513.

[4] Hu, J.L., Lin, C.H., 2008. Disaggregated energy consumption and GDP in Taiwan: a threshold cointegration analysis. Energy Economics 30,2342-2358.

[5] Narayan, P.K., Smyth, R., 2009. Multivariate granger causality between electricity consumption, exports and GDP: evidence from a panel of Middle Eastern countries. Energy Policy 37(1),229-236.

[6] http://www.stats.gov.cn/tjsj/ndsj/. National Bureau of Statistics of China.

[7] Odhiambo, N.M., 2009. Electricity consumption and economic growth in South Africa: a trivariate causality test. Energy Economics 31(5),635640.

[8] Ozturk, I., 2010. A literature survey on energy-growth nexus. Energy Policy, 340-349.

[9] Pedroni, P., 1999. Critical values for cointegration tests in heterogeneous panels with multiple regressors. Bulletin of Economics and Statistics 61, 653-670.

[10] Shiu, A., Lam, P., 2004. Electricity consumption and economic growth in China. Energy Policy 32, 47-54. Yearbooks, 2011.

[11] Yoo, S., 2006. The causal relationship between electricity consumption and economic growth in ASEAN countries. Energy Policy 34,3573-3582.

[12] Yuan, J., Kang, J.-G., Zhao, C., $\mathrm{Hu}, \mathrm{Z}$., 2008. Energy consumption and economic growth: evidence from China at both aggregated and disaggregated levels. Energy Economics 30 (6), 3077-3094.

[13] Zhang, X.-P., Cheng, X.-M., 2009. Energy consumption, carbon emissions, and economic growth in China. Ecological Economics 68 (10), 2706-2712. 